\title{
Pengaruh Religiusitas terhadap Resiliensi pada Santri Pondok Pesantren
}

\author{
Savira Annisa Putri Suprapto \\ Fakultas Psikologi, Universitas Muhammadiyah Malang \\ e-mail: Savira748@gmail.com
}

\begin{abstract}
The role of religiosity is needed to developing resilience behavior in students in Islamic boarding schools so that students can overcome existing problems despite being under pressure. One of the factors that can influence resilience is religiosity, religiosity is needed in a student as a solution if a problem occurs even though the student is in a depressed state because of the many activities carried out in Islamic boarding schools. The purpose of this research is to find out how much influence the religiosity variable has on resilience. In this study, researchers used quantitative research with a sampling technique that is stratified random sampling. In this study, researchers used boarding school students as its subjects. With a range of grades 7,8,9 in junior high school level and 10,11,12 in 221 levels of respondents in Batu City. The instruments in this study used the Seven dimension of Religiosity scale from Kendler (2003) and Connor Davidson Resilience Scale (CD-RISC 25). Analysis of the data used in this study is a simple linear regression test. The results of this study indicate that there is a significant influence between the variables of religiosity on resilience variables. ( $R 2=0.741 ; p=$ $0,000)$
\end{abstract}

KEYWORDS Religiosity, Resilience, Students of Islam

CITATION Suprapto, S.A.P. (2020). Pengaruh religiusitas terhadap resiliensi pada santri pondok pesantren. Cognicia, 8, (1), 411-421

Dewasa ini, persaingan global mengakibatkan terbentuknya kelompokkelompok masyarakat dengan kondisi dan tingkatan perekonomian yang berbeda. Terdapat beberapa tingkatan berdasarkan kondisi ekonomi masyarakat yaitu tingkatan rendah, sedang dan tinggi. Perbedaan tersebut mempegaruhi karakteristik permasalahan yang muncul pada setiap tingkatan kelompok masyarakat. Kondisi masyarakat pada tingkatan ekonomi rendah memberikan resiko stress lebih tinggi di banding pada tingkatan yang lain. Hal tersebut mempengaruhi fungsi anggota keluarga dalam kehidupan masyarakat. Morland (dalam Barnard, 1999:40) mengemukakan bahwa anak atau remaja yang berasal dari kelompok sosial-ekonomi rendah dan pernah mengalami duka cita ditinggalkan oleh orangtua, cenderung memiliki faktor resiliensi yang rendah.

Dalam menghadapi permasalahan yang terjadi dalam hidup, seseorang perlu memiliki kemampuan bertahan agar mampu beradaptasi dengan kondisinya, sehingga dapat meningkatkan potensi diri setelah menghadapi keadaan yang penuh dengan tekanan. Resiliensi adalah kapasitas untuk berkembang meskipun dalam keadaan sulit sekalipun, dan untuk mengatasi rintangan yang ada dalam kehidupan (Annalakshmi 
\& Abeer, 2011). Resiliensi menurut Vaishnavi, Connor, dan Davidson, (2007) adalah sifat yang muncul dari diri individu dalam mengatasi kesulitan yang terjadi dengan baik. Connor dan Davidson (2007) mengatakan bahwa resiliensi dapat diartikan sebagai suatu ukuran keberhasilan seseorang ketika menangani stress yang dihadapinya.

Resiliensi dapat diwujudkan sebagai upaya adaptasi yang positif dari individu atau kemampuan mengatur serta usaha agar mendapatkan kembali kesehatan mental diri kita walaupun dalam keadaan yang tertekan. Ketahanan diri juga dapat didefinisikan sebagai proses adaptasi dalam menghadapi trauma, stres, atau kesulitan (Paz, Sica, Pio, \& Fleck, 2015). Handerson dan Milstein (2003) pun mengatakan bahwa resiliensi dapat digambarkan dengan tiga macam fenomena. Pertama, hasil perkembangan positif pada diri individu yang hidup dalam lingkung beresiko tinggi. Kedua, kemampuan individu yang tetap berfungsi meski sedang di bawah stress atau tekanan. Terakhir, individu dapat sembuh atau pulih kembali dari trauma yang dialami, terutama pada individu yang trauma setelah menghadapi suatu bencana (Siregar \& Yuliarni, 2015).

Kegiatan pembelajaran di Pondok Pesantren merupakan salah satu kegiatan Setiap hari, kegiatan santri dilakukan secara mandiri dan tidak setiap saat dikontrol oleh pengurus kepesantrenan. Para santri dituntut agar bisa mengatur hidupnya sesuai dengan aturan yang berlaku di Pesantren, mulai dari cara mengatur kegiatan ibadah, kegiatan akademik, pola makan, waktu istirahat, keuangan, kesehatan, termasuk masalah psikologis dan masalah-malasah sosial yang dihadapi (Fatimah, 2016). Namun, fenomena yang terjadi di Pondok Pesantren saat ini adalah para santri merasa tidak peduli dengan adanya peraturan yang berlaku di Pondok Pesantren. Santri menganggap bahwa peraturan adalah hal yang biasa jika dilanggar, sehingga banyak santri pondok pesantren melakukan berbagai pelanggaran (Chairani dan Subandi, 2010).

Fenomena lain yang ditemukan di Pondok Pesantren adalah, terdapat beberapa santri yang sering menangis karena merasa kurang nyaman di Pondok. Selain itu, beberapa santri juga meminta pulang ketika mendapat masalah, tidak menyelesaikan masalah tersebut Bahkan ada santri yang berpura-pura sakit supaya bebas tidak mengikuti kegiatan, lalu ditemukan pula santri yang berkelahi dengan teman supaya dapat dikeluarkan dari Pondok, keluar dari Pondok tanpa ijin, bahkan yang sengaja mencuri supaya segera dikeluarkan dari Pondok. Munculnya perilaku tersebut didasari oleh kurangnya kemampuan beradaptasi dengan peraturan yang berlaku di Pondok Pesantren, teman dan lingkungan baru, keinginan untuk merasa bebas tanpa kekangan, serta kebiasaan mengantri ketika mandi ataupun menu makanan yang tidak sesuai selera (Fatimah, 2016).

Santri pondok pesantren mempunyai tugas-tugas selain menghafalkan AlQur'an juga sebagai pelajar dengan segala tugas belajarnya. Terkadang keadaan ini membuat santri yang berada di pondok pesantren merasa dirinya tertekan. Resiliensi sangat diperlukan pada santri agar mampu menyelesaikan dari permasalahan yang membuatnya tertekan. Salah satu faktor yang dapat mempengaruhi resiliensi adalah religiusitas (Hasanah, 2018). 
Aktivitas menghafal Al-Quran merupakan proses yang panjang. Penghafal AlQuran bukan semata-mata menghafal dengan mengandalkan kekuatan memori, akan tetapi juga harus menjaga hafalan yang dimiliki, memahami yang dipelajari, dan bertanggung jawab untuk mengamalkan. Proses yang panjang ini menjadi tanggung jawab yang diemban oleh penghafal Al-Quran hingga akhir hayat (Putri \& Uyun, 2017). Resiliensi sebagai salah satu faktor yang mampu mengatasi permasalahan dan tekanan yang dihadapi di Pondok Pesantren. Individu dengan tingkat resiliensi yang tinggi, dapat menyikapi setiap permasalahan yang datang dengan sikap yang positif. Untuk dapat mengendalikan perilaku yang kurang baik, kemampuan dan daya tahan ketika menghadapi tiap permasalahan yang terjadi (Prapanca, 2017).

Salah satu faktor yang mempengaruhi resiliensi adalah tingkat religiusitas dari individu. Hal tersebut sesuai dengan hasil penelitian yang menyatakan bahwa terdapat hubungan signifikan antara religiusitas dengan resiliensi pada remaja di India. Remaja yang memiliki tingkat religiusitas tinggi, cenderung memiliki kemampuan resiliensi yang baik, sehingga mampu memunculkan sikap yang positif ketika menghadapi permasalahan. Sebaliknya religiusitas yang rendah dapat memberi pengaruh terhadap kemampuan resiliensi dari individu sehingga sikap yang terbentuk pada diri individu pun nantinya cenderung lebih ke arah yang lebih negatif (Annalakshmi \& Abeer, 2011).

Resiliensi yang dimiliki oleh remaja dapat dipengaruhi oleh beberapa faktor yaitu, faktor resiko dan faktor protektif. Adapun tiga faktor yang sangat menonjol yang sudah ditemukan adalah faktor individu, keluarga, dan komunitas (McCarthy, 2009). Faktor-faktor tersebut, dapat memberikan asusmsi bahwa resiliensi dapat dipengaruhi oleh religiusitas. Herman (2011) mengatakan bahwa religiusitas termasuk ke dalam faktor pada diri individu yang mempengaruhi resiliensi. Religiusitas dapat memperkuat dan meningkatkan resiliensi jika individu meningkatkan kelekatan, kepercayaan yang dapat meningkatkan pemaknaan, harapan, dan dukungan sosial dalam komunitas spiritual (Annalakshmi \& Abeer, 2011).

Religiusitas juga telah lama menjadi topik diskusi dan penelitian pada bidang psikologi (Foy, Drescher, \& Watson, 2011). Dister (1990) mengartikan religiusitas sebagai keberagaman karena adanya internalisasi agama yang dianut seseorang ke dalam dirinya. Menurut Darmawanti (2012) individu yang selalu menjalankan perintah agamanya cenderung mampu menjalani kehidupannya dengan baik. Individu yang menjalankan komitmen agamanya ternyata memiliki stabilitas diri dan kebahagiaan hidup dibanding individu yang tidak kontinu dalam menjalankan ajaran agamanya.

Para peneliti menggambarkan aspek religiusitas sebagai proses perlindungan yang ditemukan dalam studi resiliensi di tingkat individu, keluarga, dan masyarakat (Crawford, Wright, Masten 2006). Dalam meningkatkan resiliensi pada diri individu, peran religiusitas menjadi penting, dikarenakan religiusitas dianggap sebagai salah satu faktor dari dalam diri individu yang mampu memberikan pengaruh pada resiliensi (Prapanca,2017). Secara konseptual, religiusitas dapat memfasilitasi ketahanan dalam empat cara utama: dengan membantu membangun hubungan keterikatan, dengan membuka akses ke sumber-sumber dukungan sosial, dengan 
membimbing perilaku dan nilai-nilai moral, dan dengan menawarkan peluang untuk pertumbuhan pribadi dan pengembangan (Crawford et al., 2006).

Penelitian dari Setiawan dan Pratitis (2015) mengungkapkan bahwa aspek-aspek agama sebagai coping (religius atau spiritual coping) dapat menjadi hal utama yang mempengaruhi resiliensi seseorang. Individu dengan religiusitas yang positif mampu mengendalikan emosinya, serta mampu memaknai suatu musibah yang terjadi pada dirinya menjadi suatu hal yang positif. Hal ini dikarenakan, individu mempunyai keyakinan yang kuat bahwa semua yang terjadi adalah kehendak Tuhan yang diberikan kepada mereka. Dengan adanya keyakinan ini, dapat membentuk individu menjadi seseorang yang optimis, percaya diri yang baik agar dapat mengatasi berbagai permasalahan yang terjadi saat peristiwa buruk sedang menimpa (Setiawan \& Pratitis, 2015). Hipotesis dari penelitian ini menyatakan bahwa terdapat pengaruh religiusitas terhadap resiliensi pada santri yang berada di Pondok Pesantren.

Berdasarkan beberapa fenomena dan penelitian yang sudah dijelaskan pada paragraf di atas, maka dapat disimpulkan bahwa tujuan dari penelitian ini yaitu, untuk mengetahui seberapa besar pengaruh yang diberikan oleh variabel religiusitas terhadap variabel resiliensi pada santri pondok pesantren. Manfaat dari penelitian ini dapat dibagi menjadi dua bagian, yaitu yang pertama adalah manfaat praktis dan yang kedua adalah manfaat teoritis. Manfaat praktis dari penelitian ini, sebagai bahan acuan bagi para santri pondok pesantren untuk dapat meningkatkan kemampuan resiliensi mereka, maka mereka juga perlu meningkatkan tingkat religiusitas yaitu dengan meningkatkan ibadah atau mendekatkan diri kepada Tuhan serta meningkatkan keyakinan dalam beragama sehingga dapat memperkokoh prinsip kehidupan mereka. Adapun manfaat teoritis dari penelitian ini adalah, untuk memberikan kontribusi dalam mengembangkan ilmu psikologi tentang dasar pengetahuan dari pengaruh religiusitas dan resiliensi pada santri Pondok Pesantren.

\section{METODE}

Penelitian ini merupakan penelitian kuantitatif. Penilitian kuantitatif adalah penelitian yang menggunakan angka dalam pengumpulan dan analisis datanya. Dalam metode penelitian kuantitatif peneliti menggunakan analisis regresi. Analisis regresi dipilih dalam suatu penelitian apabila peneliti ingin melihat pengaruh variabel $X$ terhadap variabel Y. Adapun subyek pada penelitian ini adalah santri yang tinggal di Pondok Pesantren. Pada penelitian ini, metode pengumpulan data yang digunakan adalah Stratified Random Sampling. Dalam metode Stratified Random Sampling, metode penarikan sampel dilakukan dengan cara membagi populasi menjadi populasi yang lebih kecil lagi (stratum), pembentukan stratum harus sedemikian rupa sehingga setiap stratum dapat dikatakan homogen berdasarkan suatu atau beberapa kriteria tertentu, kemudian dari setiap stratum nantinya diambil sampel secara acak (Nurhayati, 2008). Stratum yang dimaksud pada penelitian ini adalah tingkatan kelas 1,2,3 baik jenjang Sekolah Menengah Pertama maupun Sekolah Menengah Atas.

Subyek yang digunakan peneliti pada penelitian ini adalah santri yang berada di Pondok Pesantren. Subjek berada pada jenjang SMP sampai dengan jenjang SMA, dari kelas 1 - 3 Sekolah Menengah Pertama (SMP) dan kelas 1 -3 dari jenjang Sekolah Menengah Atas (SMA). Keseluruhan subjek berjumlah 221 orang. 
Religiusitas merupakan keberagaman yang terbentuk dan dapat diinternalisasikan ke dalam diri subyek kemudian dieksternalisasikan berupa suatu sikap dan perilaku sebagai pengabdian subyek terhadap agama yang dianutnya dan agama yang diyakininya. Religiusitas dapat diukur dengan skala Seven dimension of Religiosity berdasarkan aspek yang dikemukakan oleh (Kendler, 2003) menggunakan lima poin skala Likert. Jumlah keseluruhan aitem pada skala ini berjumlah 62 aitem. Setelah selesai melakukan uji validitas dan reliabilitas oleh peneliti, diperoleh hasil yaitu tingkat validitas skala Seven dimension of Religiosity antara 0,496 - 0,899 dan nilai dari uji reliabilitas 0,984 dan menunjukan 62 item yang valid.

Resiliensi merupakan kemampuan ketahanan diri untuk menghadapi kesulitankesulitan atau stressor yang muncul, sehingga dapat mengatasi permasalahan tersebut dengan baik walaupun subyek sedang dalam kondisi yang tertekan. Resiliensi diukur dengan menggunakan skala oleh Connor Davidson Resilience Scale (CD-RISC 25) berdasarkan beberapa aspek yang telah ditentukan oleh Connor dan Davidson (2003), pertama, kompetensi personal meliputi standar yang tinggi subyek dan keuletan dari diri subyek. Kedua, kepercayaan terhadap diri sendiri yang meliputi, individu mampu mempunyai toleransi terhadap efek negatif yang ada di dalam kehidupannya, dan mampu menghadapi stress yang terjadi. Ketiga, individu dapat menerima adanya perubahan yang positif dan mampu menjalin hubungan aman terhadap orang lain. Keempat, yaitu pengendalian diri dari individu. Terkahir, adanya pengaruh spiritual dalam diri individu. Skala resiliensi pada penelitian ini terdiri dari 25 aitem, dengan 5 rentang jawaban. Tingkat validitas dari skala CD-RISC 25 nilainya berkisar dari 0,493 0,828 dan nilai dari uji reliabilitas pada skala ini adalah 0,966. Hasil tersebut menunjukan bahwa terdapat 25 item yang dapat dikatakan valid.

Penelitian yang dilakukan memiliki tiga prosedur utama sebagai berikut. Tahap persiapan, dimulai dari peneliti melakukan pendalaman materi melalui kajian teoritik. Peneliti menyusun dan mengembangkan alat ukur berdasarkan aspek yang terdapat pada variabel yang peneliti ambil, selanjutnya peneliti melakukan pengambilan data di beberapa Pondok Pesantren secara acak. Pada tahap mengadaptasi skala dari skala internasional berbahasa Bahasa Inggris, yang pertama dilakukan oleh peneliti adalah menerjemahkan skala tersebut ke Bahasa Indonesia, kemudian peneliti memberikan skala tersebut kepada expert judgement. Hal ini dilakukan untuk mengurangi aitemaitem yang dirasa ambigu di dalam skala. Setelah mendapatkan hasil dari expert judgement, maka peneliti melakukan uji try out dengan memberikan skala kepada responden agar dapat diuji nilai validitas dan reliabilitas dari instrumen yang digunakan untuk mengumpulkan data. Pada tahap penyebaran skala try out, skala diberikan secara langsung kepada santri yang tinggal di Pondok Pesantren di Batu, Malang.

Tahap selanjutnya yaitu pelaksanaan penelitian. Setelah instrumen atau skala selesai diuji dan dinyatakan valid serta reliabel, maka peneltiti melakukan pengambilan data dengan cara menyebar kedua skala yang telah dinilai uji validitas dan reliabilitas kepada responden penelitian. Pada tahap menganalisa data, peneliti menganalisa seluruh data menggunakan analisa statistik dari hasil data yang telah didapatkan. Data-data yang telah diperoleh kemudian diinput dan diolah dengan menggunakan program perhitungan statistik SPSS (Statistical Program for Sosial 
Science), menggunakan analisis regresi linear. Regresi linear adalah analisis yang dapat memperkirakan seberapa besar koefesien yang dapat dihasilkan dari persamaan yang sifatnya linier dan melibatkan satu variabel bebas yang digunakan sebagai alat agar dapat memperkirakan seberapa besar nilai dari variabel terikat (Muhid, 2012).

HASIL

Tabel 1. Deskripsi Subjek Penelitian

\begin{tabular}{lcc}
\hline \multicolumn{1}{c}{ Kategori } & Frekuensi & Presentase \\
\hline Usia & & \\
$13-15$ & 47 & $21 \%$ \\
$16-18$ & 167 & $76 \%$ \\
$19-21$ & 7 & $3 \%$ \\
\hline Jenis Kelamin & & \\
$\quad$ Perempuan & 174 & $78,8 \%$ \\
Laki-Laki & 47 & $21,2 \%$ \\
\hline Kelas & & \\
$7-9$ & 26 & $11,8 \%$ \\
$10-12$ & 195 & $88,2 \%$ \\
\hline Anak ke- & & \\
1 & 92 & $41,7 \%$ \\
2 & 20 & $9 \%$ \\
3 & 10 & $4,5 \%$ \\
4 & 67 & $30,3 \%$ \\
5 & 32 & $14,5 \%$ \\
\hline
\end{tabular}

Tabel 2. Kategorisasi Variabel

\begin{tabular}{ccccc}
\hline Variabel & Kategori & Interval & Frekuensi & Presentase \\
\hline \multirow{2}{*}{ Religiusitas } & Rendah & $62-186$ & 95 & $43 \%$ \\
& Tinggi & $187-248$ & 126 & $57 \%$ \\
\hline \multirow{2}{*}{ Resiliensi } & Rendah & $25-75$ & 46 & $21 \%$ \\
& Tinggi & $76-125$ & 175 & $79 \%$ \\
\hline
\end{tabular}

Hasil penelitian kedua variabel diketahui frekuensi terbanyak terdapat pada kategori tinggi yaitu variabel resiliensi berjumlah 175 responden dengan nilai interval 76-125 dengan presentase 79\% dan 46 responden berada pada kategori rendah dengan persentase $21 \%$. Sedangkan pada variabel religiusitas berjumlah 126 responden dengan nilai interval 187-248 dengan presentase $57 \%$ dan 95 responden berada pada kategori rendah dengan persentase $43 \%$.

Tabel 3. Uji Regresi

\begin{tabular}{cccc}
\hline$r^{2}$ & Sig. & $\mathbf{N}$ & Simpulan \\
\hline 0,741 & 0,000 & 221 & Significant \\
\hline
\end{tabular}


Berdasarkan data pada tabel 3, terdapat hasil adanya pengaruh positif dan signifikan antara religiusitas dengan resiliensi dimana nilai yang didapatkan sebesar $p$ $=0,000$. Dari hasil ini menjelaskan bahwa hipotesa yang terdapat dalam penelitian ini diterima, dimana para santri pondok pesantren yang mempunyai religiusitas tinggi maka resiliensi yang dimiliki pun tinggi dan sebaliknya jika religiusitas dari para santri rendah maka resiliensinya pun berada di tingkat rendah. Kontribusi dari religiusitas terhadap variabel resiliensi sebesar $74,1 \%\left(\mathrm{r}^{2}=0,741\right)$ sedangkan $25,9 \%$ lainnya dipengaruhi oleh variabel lain diluar yang dilakukan dalam penelitian ini.

\section{DISKUSI}

Berdasarkan hasil penelitian yang telah dilakukan oleh peneliti, dapat diketahui adanya pengaruh signifikan antara religiusitas dengan resiliensi. Nilai pengaruh dari kedua variabel tersebut sebesar $74,1 \%$ dan nilai signifikansi sebesar 0,000 . Hal tersebut sejalan dengan hipotesis yang diajukan peneliti, para santri pondok pesantren yang memiliki keyakinan kuat terhadap agamanya, cenderung memiliki kemampuan untuk menghadapi dan dapat mengatasi permasalahan maupun tekanan yang terdapat dalam diri maupun lingkungan. Semakin tinggi tingkat religiusitas para santri, berpengaruh terhadap tingginya tingkat resiliensi pada santri yang tinggal di Pondok Pesantren, begitu pula sebaliknya.

Penelitian ini mendukung penelitian sebelumnya oleh Sangwon Kim (2012), yang mengatakan bahwa resiliensi telah mengidentifikasi agama dan spiritualitas sebagai faktor terbentuknya resiliensi seseorang. Menurut Sangwon Kim (2012) religiusitas pada remaja juga berfungsi sebagai sumber ketahanan pada remaja yang berfokus pada pengaruh religiusitas terhadap hubungan dekat, dukungan sosial, perilaku moral, pertumbuhan pribadi, adaptasi koping, dan pengembangan makna dan tujuan hidup.

Penelitian lain yang dilakukan oleh Hasanah (2018) menyimpulkan bahwa terdapat hubungan positif dan signifikan antara religiusitas dengan resiliensi pada santri penghafal Al-Qur'an di Pondok Pesantren Sunan Drajat Lamongan. Hubungan ini berkorelasi positif yang artinya semakin tinggi religiusitas santri penghafal $\mathrm{Al}$ Quran, maka semakin tinggi juga resiliensi dari santri penghafal Al Quran. Begitupula kebalikannya, semakin rendah religiusitas santri penghafal Al Quran maka semakin rendah resiliensi dari santri penghafal Al Quran (Hasanah, 2018). Pada penelitian tersebut didapatkan sumbangan efektif antara religiusitas terhadap resiliensi sebesar $12,3 \%$, ditunjukkan oleh koefisien determinan $\left(\mathrm{r}^{2}\right)=0,123$.

Perbedaan pada penelitian sebelumnya dengan penelitian yang peneliti lakukan adalah, peneliti sebelumnya hanya memakai subjek santri pernghafal Al-Qur'an saja. Namun, disini peneliti menggunakan santri Pondok Pesantren dengan target hafalan Al-Qur'an yang tinggi yaitu 15 juz dan harus dicapai dalam kurun waktu 2 tahun, sedangkan para santri juga memiliki tuntutan pada bidang akademik yang tinggi, dikarenakan para santri juga mengikuti olimpiade-olimpiade yang ada di Jawa Timur.

Penelitian lain yang dilakukan oleh Van Dyke \& Elias (2007) menyebutkan bahwa, religiusitas dapat dikatakan sebagai sumber resiliensi dari manusia adalah bahwa religiusitas berfungsi sebagai penanggulangan seseorang untuk menghadapi kesulitan. Dapat disimpulkan dari hasil penelitian di atas bahwa religiusitas dapat 
menjadikan resiliensi sebagai modal sebagai pencegahan dan dapat mengatasi permasalahan atau kesulitan yang terjadi. Jika religiusitas seseorang tinggi maka semakin tinggi pula tingkat resiliensi dari seseorang tersebut.

Berdasarkan hasil yang didapat pada penelitian ini, menunjukan bahwa bahwa subjek perempuan lebih tinggi dalam tingkat religiusitasnya dari pada subjek laki-laki. Hal ini didukung dengan sebuah penelitian yang dilakukan oleh Jhon W. Santrock (2012), memperoleh hasil bahwa remaja putri memiliki tingkat religiusitas lebih tinggi daripada remaja putra. Dikarenakan remaja putri lebih sering mengunjungi tempat ibadah, menganggap agama akan membentuk pola kehidupan sehari-hari mereka, berpartisipasi di dalam kelompok keagamaan, lebih sering berdo'a dan lebih mendekatkan diri kepada Tuhan.

Berdasarkan hasil analisa yang telah didapatkan, dapat menjelaskan bahwa kontribusi variabel religiusitas terhadap resiliensi memiliki nilai sebesar 74,1\% yang dapat diartikan bahwa variabel religiusitas memengaruhi resiliensi, sedaangkan 25,9\% dipengaruhi oleh faktor lain. Faktor lain yang mempengaruhi sebagaiman disebutkan dalam penelitian Rahmawati, Listiyandini, \& Rahmatika (2019) bahwa resiliensi psikologis menghasilkan peranan yang lebih besar terhadap dimensi kesejahteraan fisik pada remaja panti asuhan dibandingkan dimensi lain. Dengan memiliki resiliensi psikologis yang tinggi, remaja panti asuhan akan lebih mampu mempertahankan kesehatan dan energi ketika berada di bawah tekanan. Penelitian oleh Mujahidah \& Listiyandini (2018) mendapatkan hasil resiliensi dan empati, khususnya empati afektif, berpengaruh signifikan terhadap tingkat gejala depresi pada remaja dengan kontribusi efektif sebesar 5.5\%. Dalam hal ini, empati afektif berpengaruh pada munculnya gejala depresi yang lebih tinggi. Namun sebaliknya, resiliensi berpengaruh pada menurunnya gejala depresi. Hasil ini mengindikasikan bahwa pengaruh empati afektif yang dapat meningkatkan terjadinya gejala depresi diprediksi akan berkurang jika terdapat resiliensi yang tinggi.

Kelebihan pada penelitian yang dilakukan oleh peneliti adalah belum banyak peneliti yang menggabungkan kedua variabel ini untuk diteliti menggunakan subjek santri Pondok Pesantren dengan target hafalan dan prestasi akademi yang tinggi. Keterbatasan yang terdapat pada penelitian ini adalah hasil penelitian belum dapat berlaku secara universal, hal ini dikarenakan pengambilan sampel dilakukan hanya di satu daerah saja.

\section{SIMPULAN}

Berdasarkan penelitian yang dilakukan, dapat disimpulkan bahwa hasil penelitian sesuai dengan hipotesa yang diajukan, yaitu terdapat pengaruh religiusitas terhadap resiliensi, dimana ketika seseorang memiliki tingkat religiusitas yang tinggi maka resiliensi yang dimiliki juga tinggi. Namun, jika seseorang memiliki tingkat religiusitas rendah, maka berpengaruh terhadap rendahnya tingkat resiliensi. 


\section{REFERENSI}

Annalakshmi, N., \& Abeer, M. (2011). Islamic worldview, religious personality and resilience among Muslim adolescent students in India. Europe's Journal of Psychology, 7(4), 716738. https://doi.org/10.5964/ejop.v7i4.161

Barnard, P., Morland, I., \& Nagy, J. (1999). Children, Bereavement and Trauma: Nurturing Resilience. London: Jessica Kingsley Publisher.

Bravo, A. J., Pearson, M. R., \& Stevens, L. E. (2016). Making religiosity person-centered : A latent pro fi le analysis of religiosity and psychological health outcomes. PAID, 88, 160-169. https://doi.org/10.1016/j.paid.2015.08.049

Chairani, L. \& Subandi, M. A. (2010). Psikologi santri penghafal al-Qur'an: Peranan regulasi diri. Yogyakarta: Pustaka Pelajar.

Connor, K. M., \& Davidson, J. R. T. (2003). Development of a new Resilience scale: The ConnorDavidson Resilience scale (CD-RISC). Depression and Anxiety, 18(2), 76-82. https://doi.org/10.1002/da.10113

Crawford, E., Wright, M., \& Masten, A. S. (2006). Resilience and spirituality in youth. In E.C. Roehlkepartain, P. E., King, L. Wagener., \& P. L. Benson (Eds.), The handbook of spiritual development in childhood and adolescence (pp. 355 - 370). Thousand Oaks, CA: Sage.

Darmawanti, I. (2012). Hubungan Antara Tingkat Religiusitas Dengan Kemampuan Dalam Mengatasi Stress.

Dister, A. S. 1990. Pengalaman dan Motivasi Beragama. Yogyakarta: Kanisius

Fatimah, S. (2016). Keterampilan memecahkan masalah pada santri di tahun pertama memasuki pondok pesantren. Retrieved from http://eprints.ums.ac.id/41780/1/02. Naskah Publikasi.pdf

Fistara, E. A. (2018). Pengaruh Komitmen Beragama Terhadap Resiliensi Perempuan Muslimah Bercadar. Journal Psychology.

Foy, D. W., Drescher, K. D., \& Watson, P. J. (2011). resilience, (February 2018). https://doi.org/10.1017/CBO9780511994791.008

Glock, Y.C \& Stark, R. (1968). American Piety: The Nature of Religious Commitment. https://doi.org/10.1093/sf/47.2.232.

Grotberg, E (1995). A Guide to Promoting Resilience in Children : Strengthening the Human Spirit. The Series Early Childhood Development : Practice and Reflections. The Hague: Benard van Leer Voundation.( 1999 ). Tapping Your Inner Strength. Oakland, CA : New Harbinger Publication, Inc.

Hasanah, M. (2018). Hubungan antara religiusitas dengan resiliensi santri penghafal al-qu'ran di pondok pesantren, 978-602-60, 84-94.

Henderson, E., \& Milstein, M. M. (2003). Resiliency in School. Thousand Oaks, CA: Sage Publications.

Herman, H., Stewart, D. E., Diaz-Granados, N., DPhill, E. L. B., Jackson, B., \& Yuen, T. (2011). What is Resilience? Canadian Journal of Psychiatri, 56, (5), (258-265).

Kasen, S., Wickramaratne, P., Gameroff, M. J., and Weissman, M. M. (2013). Religiosity and resilience in persons at high risk for major depression, 42(3), 509-519. https://doi.org/10.1017/S0033291711001516.Religiosity

Kendler, K. S., Liu, Z., Gardner, C. O., \& Mccullough, M. E. (2003). Dimensions of religiosity ad their relationship to lifetime psychiatric and s ... Library, (March), 496-503.

KIM, S. (2012). Salt minerals and their genesis of the Permian Fengcheng Formation in Urho area, Junggar Basin. Kuangwu Yanshi/ Journal of Mineralogy and Petrology, 32(2), 105114. https://doi.org/10.1002/pits

Muhid, A. (2012). Analisis statistik: 5 langkah praktis analisis statistik dengan SPSS for windows. Surabaya: Zifatama publishing. 
Mujahidah, E., \& Listiyandini, R. A. (2018). Pengaruh resiliensi dan empati terhadap Gejala depresi pada remaja, Volume 14(June). https://doi.org/10.24014/jp.v14i1.5035

Nurhayati. (2008). Studi Perbandingan Metode Sampling antara Simple Random dengan Stratified Random. ICT Research Center UNAS, Vol.3(1), Hal. 20. https://doi.org/10.1242/dev.100743

Pargament, K. I. (1997). The psychology of religion and coping: Theory, research, practice. New York: The Guildford Press.

Pardini, D. A., Plante, T. G., Sherman, A., \& Stump, J. E. (2000). Religious faith and spirituality in substance abuse recovery. Journal of Substance Abuse Treatment, 19(4), 347-354. https://doi.org/10.1016/S0740-5472(00)00125-2

Paz, B., Sica, N., Pio, M., \& Fleck, D. A. (2015). Intrinsic religiosity, resilience, quality of life , and suicide risk in depressed inpatients. Journal of Affective Disorders, 179, 128-133. https://doi.org/10.1016/j.jad.2015.03.022

Prapanca, P. (2017). Pengaruh Tingkat Religiusitas Terhadap Self Resiliensi Siswa Kelas X Sekolah Menengah Atas Negeri 2 Karanganyar the Effect of Religiousity on X Grader Student Self-Resilience in the High, 62-70.

Prasetyo, H. C. (2016). Hubungan antara religiusitas dan resiliensi pada individu yang gagal dalam seleksi kepolisisan di surakarta, 802011098.

Putri, A. S., \& Uyun, Q. (2017). Hubungan Tawakal dan Resiliensi pada Santri Remaja Penghafal Al-Quran di Yogyakarta. Jurnal Psikologi Islam, 4(1), 77-87.

Rahmawati, D. B., Listiyandini, R. A., \& Rahmatika, R. (2019). Resiliensi Psikologis dan Pengaruhnya terhadap Kualitas Hidup terkait Kesehatan pada Remaja di Panti Asuhan, (June). https://doi.org/10.31289/analitika.v11i1.2314

Reich, J. W., Zautra, A. J., \& Hall, J.S. (2010) Handbook of Adult Resilience. New York: The Guilford Press.

Reivich, K \& Shatte, A. (2002). The Resilience Factor: 7 Essential Skills for Overcoming Life's Inevitacles Obstacles. New york: Broadway Books.

Santrock, John W. 2012. Life-Span Development Edisi Bahasa Indonesia. Jakarta: Erlangga

Setiawan, A., \& Pratitis, N. T. (2015). Religiusitas, Dukungan Sosial dan Resiliensi Korban Lumpur Lapindo Sidoarjo. Jurnal Psikologi Indonesia, 4(02).

Siregar, R. H., \& Yuliarni, R. (2015). Hubungan antara religiusitas dan resiliensi pada penyintas erupsi gunung sinabung. Psikologia, 10(7), 92-98.

Smet, B. (1994). Psikologi Kesehatan. Jakarta: PT. Grasindo Sundberg,

Sugiyono. (2012). Metode penelitian kuantitatif kualitatif dan R\&B. Bandung: Alfabeta.

Vaishnavi, S., Connor, K., \& Davidson, J. R. T. (2007). An abbreviated version of the ConnorDavidson Resilience Scale (CD-RISC), the CD-RISC2: Psychometric properties and applications in psychopharmacological trials. Psychiatry Research, 152(2-3), 293-297. https://doi.org/10.1016/j.psychres.2007.01.006

Van Dyke, C. J., \& Elias, M. J. (2007). How forgiveness, purpose, and religiosity are related to the mental health and well-being of youth. A review of literature. Mental Health Religion Culture, 10(4), 395-415.

Wals, F .(2003). Family Resilience: A framework for clinical practice. Family Process.

Whitehouse, H. (2005). The Cognitive Foundations of Religiosity, 05-022 Ch, 207-232. 